\title{
Biomateriaalien käyttö öljyä sitovina suodattimina
}

\author{
Antti Pasila, Mikko Hautala ja Aarne Pehkonen
}

Helsingin yliopisto, Maa- ja kotitalousteknologian laitos

Pl. 27, 00014 Helsingin yliopisto, antti.pasila@ helsinki.fi

\section{Ydin}

Tutkimuksessa on selvitetty kuitukasveista valmistettujen biomateriaalien käyttöä öljyä imevinä suodattimina. Suomen viljelyolosuhteet tarjoavat mahdollisuuden prosessoida täällä viljeltävistä kasveista erikoismateriaaleja, jotka soveltuvat esimerkiksi öljyä sitoviksi suodatinaineiksi. Kuitukasveista on mahdollista valmistaa suodattimia, jotka sitovat itseensä enemmän öljyä kuin vettä.

\section{Johdanto}

Suomen merialueiden lähellä lisääntyvät öljynkuljetukset aiheuttavat riskin, jonka torjumiseen on varauduttava. Öljykuljetusten jäljiltä vedestä ja rannoilta joudutaan keräämään öljyä esimerkiksi imeyttämällä sitä erilaisiin biomateriaaleihin. Myös maaperään pääsevien öljypäästöjen torjuminen on Suomessa tärkeää runsaiden ja toistaiseksi hyvälaatuisten pohjavesivarojemme takia.

Pohjoisissa oloissa viljellyistä kuitukasveista voidaan valmistaa materiaaleja, jotka rakenteeltaan sopivat öljyn imeytys- ja suodatinaineiksi. Tutkimuksessa on kehitetty menetelmä, jossa vesi puhdistetaan öljystä yksinkertaisella biomateriaalisuodattimella. Tässä tutkimuksessa on mitattu kuitukasveista valmistettujen suodatinaineiden ominaisuuksia öljyn sitomisessa.

Biomateriaaleista valmistetut suodatinaineet näyttävät soveltuvan öljyn imeytykseen yhtä hyvin kuin jo markkinoilla olevat valmisteet. Kuitukasveista valmistetut suodatinaineet ovat edullisia, koska niiden valmistus perustuu dry-line -menetelmään ${ }^{\circledR}$ (Pasila 1997, Pasila ja Kymäläinen 2000), jossa vältytään materiaalin kuivaukselta. Lisäksi materiaalin pintarakenne muuttuu siten, että se sitoo tehokkaasti öljyä. Uusi suodatinaine, sen valmistusmenetelmä ja sovellutuksia on patentoitu (Pasila 1998).

Tulokset ovat sovellettavissa helposti käytäntöön. Logistisesti loppukäytön kannalta välttämätön hajautettu varastointi ja öljyn torjuntavalmius olisi mahdollista toteuttaa valmistuspaikoilla, esimerkiksi maatiloilla. Uudesta menetelmästä on kehitettävissä vientituote, jolle lähitulevaisuudessa on todennäköisesti käyttöä Itämeren rannikoilla. Öljyvuodon sitominen heti alkuvaiheessa olisi kaikin puolin parempi ratkaisu kuin öljyn pääsy vesistöön, maahan tai viemärijärjestelmiin. Öljyn imeyttäminen vuodon alkulähteellä on mahdollista yksinkertaisella ja halvalla teknologialla.

\section{Aineisto ja menetelmät}

Tutkimuksessa verrattiin eri korjuuteknologioiden ja kasvinosien vaikutusta öljyn sitomisominaisuuksiin. Tavoitteena on myös tunnistaa sellainen luonnollinen rakenne, joka sopii mahdollisimman vähillä prosessoinneilla öljyn imeytykseen. Tutkimuksessa käytettiin seuraavaa käsittelyä:

\section{Suodatinaine Käsittely \\ Pellavan varret Syys- tai kevätkorjuu + vasaramylly + kuidun erottaminen + päistäreen lajittelu}

Suodatuskokeissa vasaramyllyllä jauhetuista pellavan korsista valmistettiin syväsuodattimen kaltainen suodatinpanos, jonka läpi valutettiin veden ja öljyn seosta. Menetelmä oli sama kuin aiemmin öljyn imeytymistä tutkittaessa (VTT 1996). Perusteluna menetelmälle olivat ne käytännön olosuhteet, joissa tällaisia suodattimia käytetään. Öljyn ja veden imeytystulokset on esitetty samalla tavalla kuin aiemmassa tutkimuksessa (Choi, ym. 1993), jossa tutkittiin puuvillamaton ja synteettisten imeytysaineiden ominaisuuksia. 


\section{Suodatinaineiden valmistus}

Suodatinainetta valmistettiin jauhamalla pellavan, kuituhampun ja ruokohelpin varsia vasaramyllyllä, jossa oli 12 mm:n seula (kuva 1) (Pasila, ym. 1999, s. 59). Jauhamisen jälkeen kasvimateriaali lajiteltiin rumpuerottelijalla. Prosessoidun raaka-aineen kosteus oli n. $10 \%$ w.b..

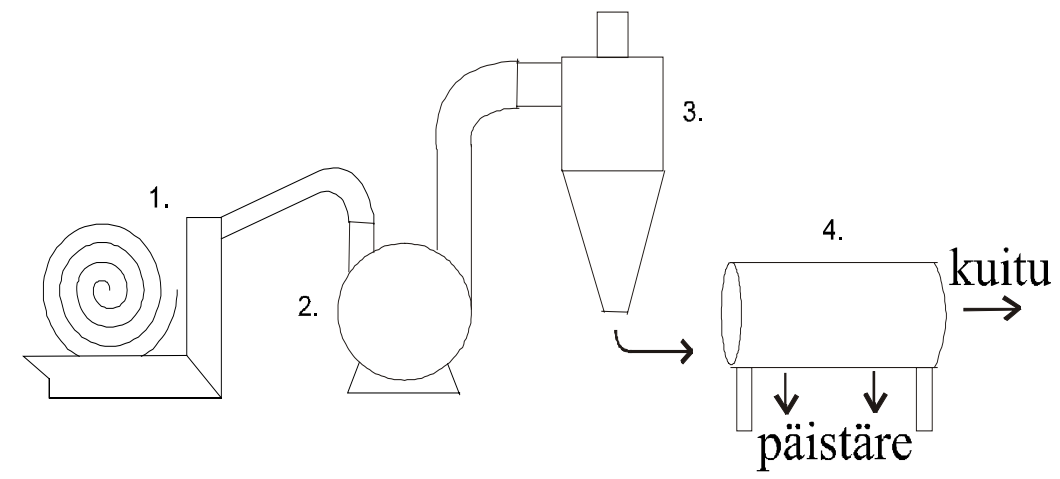

Kuva 1. Periaatekuva laitteistosta pellavan varsien ja lajitteluun. 1. pyöröpaalin purkain, 2. vasaramylly, 3. sykloni, 4 rumpuerottelija (PASILA, ym. 1999, s. 59).

Pellavasta käytettiin suodatinaineina päistärejakeita. Pellavan ja kuituhampun pintaosien pitkiä kuituja (10-25 mm) on pidetty sopivampina esimerkiksi lämmöneristeiden tai sellumassan valmistukseen (mm. Rissanen ja Viljanen 1998, Groot 1999, Gullichsen, ym. 2000). Taulukossa 1 on esitetty kokeissa käytetyt suodatinaineet.

\section{Suodatinaineiden ominaisuudet}

Mittauksissa käytetyt suodatinaineet olivat pellavan päistäreitä. Kaikkea kuitua ei kuitenkaan saatu poistetuksi, sillä osa pitkistä kuiduista oli sekoittunut päistäreisiin niin tiukasti, ettei niitä saatu erotetuksi. Ruokohelpin varressa ei ole pitkiä kuituja, joten siitä ei muodostunut yli $5 \mathrm{~mm}$ jaetta. Tuloksena saatujen materiaalien jakaumat poikkesivat toisistaan (kuva 2). Kasvit ovat fysikaaliselta rakenteeltaan hauraita tai sitkeitä (Niklas 1992, p. 102). Näihin fysikaalisiin ominaisuuksiin näyttää vaikuttavan kasvin korjuuaika. Eroja hauraudessa ja sitkeydessä on myös jakeissa, siten, että pellavan ja kuituhampun pintakuidut ovat sitkeitä.. Biomateriaaleista lajittelussa muodostuneet jakeet punnittiin. Kuvassa 2 on esitetty lajittelun jäljiltä muodostuneiden jakeiden osuudet .

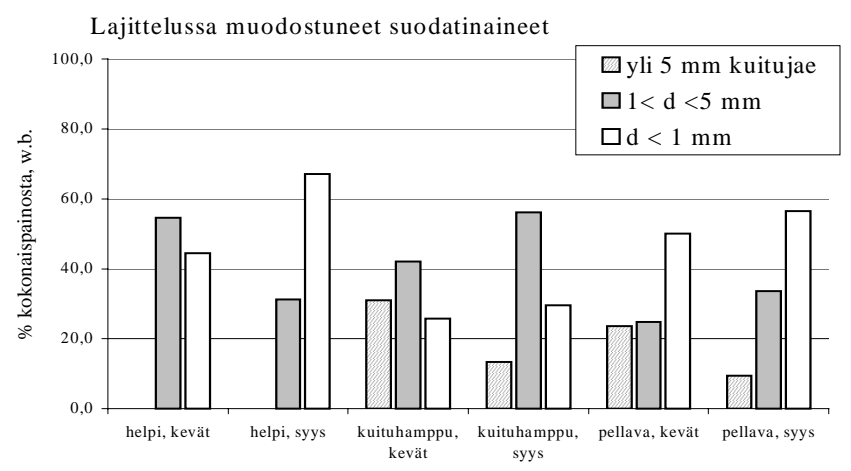

Kuva 2. Suodatinaineiden lajittelussa muodostuneet jakeet \% lajittelemattomasta erästä. Kuitujakeet on merkitty kaavioon vinoviivoituksella. Kuitujakeita ei käytetty suodatinaineina.

\section{Suodatuskoe}

Suodatinaineiden läpi valutettiin 10W-30 moottoriöljyn ja 10W-30 jäteöljyn seoksia. Suodatuskoe tehtiin seuraavasti: Näytteiden ja suodatettavan öljy-vesiseoksen määrät punnittiin ennen koetta. Mittalasista voitiin lukea suodattimen läpi valunut nestemäärä. Suodattimesta mittalasiin valunut neste mitattiin 1, 2, 5, 10, 20, 50, 100, 200, 500 ja 1000 min:n jälkeen suodatuksen aloittamisesta. 


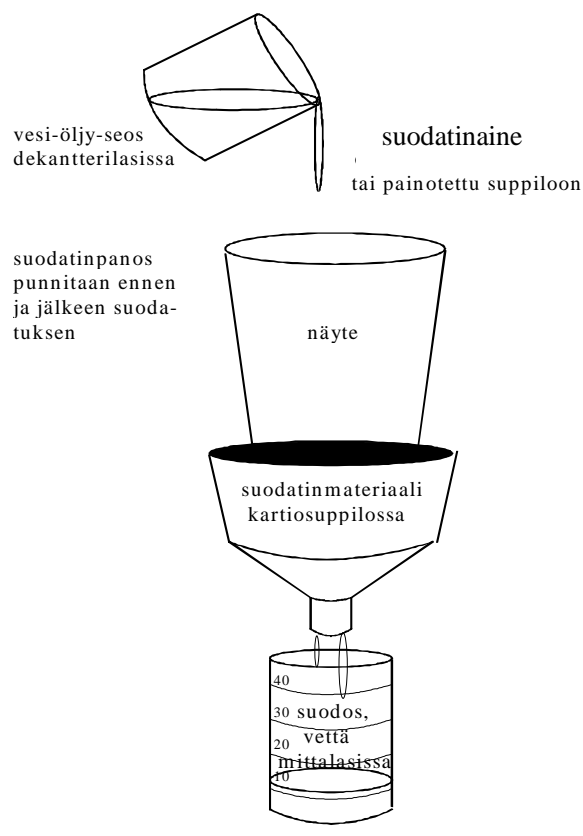

Kuva 3. Suodatuskokeen järjestelyt. Öljy-vesiseos valutettiin suodatinaineen läpi.

\section{Tulokset}

Suodatinaineiden sitoma nestemäärä taulukossa 1 on ilmoitettu 1000 min:n valutusajan jälkeen. Lisäksi taulukossa on öljyn ja veden yhteismäärä sekä öljyn ja veden imeytymisen suhde.

Taulukko 1. Suodatinaineiden sitomat 10W-30 öljy, vesi sekä imeytyneiden 10W-30 öljyn ja veden suhde. Lisäksi on esitetty mittausten keskihajonnat (s.d.), $n=3$.

\begin{tabular}{|l|c|c|c|c|c|}
\hline näyte & $10 \mathrm{~W} 30$ & $10 \mathrm{~W} 30$ s.d. & vesi & vesi, s.d. & öljy/vesi \\
\hline pellava 1 mm kevät & 2,3 & 0,31 & 1,9 & 0,14 & 1,2 \\
\hline pellava 5 mm kevät & 1,9 & 0,13 & 1,4 & 0,25 & 1,4 \\
\hline pellava 1 mm syys & 2,7 & 0,32 & 2,0 & 0,30 & 1,4 \\
\hline pellava 5 mm syys & 2,1 & 0,21 & 0,9 & 0,05 & 2,3 \\
\hline k.hamppu 1 mm kevät & 2,8 & 0,31 & 3,0 & 0,08 & 0,9 \\
\hline k.hamppu 5 mm kevät & 1,7 & 0,05 & 1,6 & 0,16 & 1,1 \\
\hline k.hamppu 1 mm syys & 3,1 & 0,08 & 3,0 & 0,15 & 1,0 \\
\hline k.hamppu 5 mm syys & 1,7 & 0,38 & 1,7 & 0,46 & 1,0 \\
\hline r.helpi 1 mm, kevät & 3,8 & 0,10 & 2,1 & 0,10 & 1,8 \\
\hline r.helpi 5 mm, kevät & 2,2 & 0,20 & 0,9 & 0,11 & 2,4 \\
\hline r.helpi 1 mm syys & 3,2 & 0,29 & 2,2 & 0,15 & 1,5 \\
\hline r.helpi 5 mm syys & 1,9 & 0,40 & 1,4 & 0,21 & 1,4 \\
\hline
\end{tabular}

Suodatinaineiden sitoma öljymäärä taulukossa 1 on välillä $1,7-3,8 \mathrm{~g} / \mathrm{g}$, vaihtelua on siis noin tekijän kaksi verran. Paras öljyn sitoja oli kevätkorjattu $1 \mathrm{~mm}: n$ ruokohelpijae. Suhteellisesti öljyn ja veden sitomisen suhde oli suurin $5 \mathrm{~mm}: n$ kevätkorjatulla ruokohelpillä, n. 2,4 -kertainen. Pellavan ja ruokohelpin selektiivisyys öljyn sidonnassa muihin koejäseniin verrattuna on keskihajontojen perusteella tilastollisesti merkittävää.

\section{Tulosten tarkastelu}

Nesteensitomiskyky kuvaa suodatinaineiden ominaisuuksia. Öljyn erottamisessa vedestä suodatinaineen selektiivisyys on kuitenkin nesteensitomiskykyä tärkeämpi ominaisuus. Suodatinaineen tulisi sitoa mahdollisimman vähän vettä ja mahdollisimman paljon öljyä. Öljyn imeytymisen mittaamiseen on 
aiemminkin käytetty syväsuodattimen tyyppistä biomateriaaleista valmistettua suodatinpanosta (VTT 1996). Aiemmissa tutkimuksissa tavoitteena on ollut selvittää biomateriaalien ominaisuuksia vedessä olevien vähäisten (400 mg/l) öljypitoisuuksien poistamiseen.

Mitatuista suodatinaineista käyttökelpoisimpia öljyn sitomiseen $1 \mathrm{~mm}: \mathrm{n}$ kevätkorjattu ruokohelpi sekä selektiivisyytensä perusteella $5 \mathrm{~mm}: n$ pellava- ja ruokohelpijakeet, jotka sitovat n. 2,5 kertaa enemmän öljyä kuin vettä. Molemmissa 5 mm:n jakeissa on jäljellä paljon kasvin varsien alkuperäistä pintaa. Selityksenä hyvään öljyn sitomiskykyyn saattaa olla varren ehjänä säilynyt vahamainen pinta, joka hylkii vettä ja sitoo öljyä.

Suomessa viljellyistä kuitukasveista on tämän tutkimuksen tulosten perusteella mahdollista valmistaa öljyn sidonta-aineita, jotka imevät itseensä enemmän öljyä kuin vettä. Tutkimuksessa selvitettiin mitkä suodatinaineiden ominaisuudet vaikuttavat öljyn sitoutumiseen. Korrelaatioanalyysissä vertailtiin suodatinaineiden vahapitoisuuksia, tuhkapitoisuuksia, kosketuskulmia öljyn ja veden suhteen sekä tilavuuspainoa suodatinaineiden öljyn sitomisarvoihin. Vahvin korrelaatio, 0,82 oli tuhkapitoisuuden ja öljynsitomisarvojen välillä. Tämä aiheutuu ilmeisesti suodatinaineen piitä sisältävän hienoaineen öljyä sakeuttavasta vaikutuksesta. Vahapitoisuuden ja öljynsitomisarvojen välinen korrelaatio oli 0,72. Mittaustuloksista tehtiin myös regressioanalyysit, joka osoittivat, että suodatinaineen $10 \%$-yksikön tuhkapitoisuuden nousu lisää öljyn sitoutumista $1,7 \mathrm{~g} / \mathrm{g}$ suodatinainetta. Samoin suodatinaineen $1 \%$-yksikön vahapitoisuuden nousu lisää öljyn sitoutumista $1,2 \mathrm{~g} / \mathrm{g}$ suodatinainetta.

\section{Johtopäätökset}

Biomateriaalien prosessointi suodatinkäyttöön edellyttää laitteita, joilla haluttuja ominaisuuksia sisältävät kasvinosat voidaan irrottaa ja erottaa toisistaan. Biomateriaalien käsittelyssä tarvitaan aiempaa suurempaa tarkkuutta ja kykyä erottaa fysikaalisilta tai kemiallisilta ominaisuuksiltaan erilaisia kasvinosia. Tähän tarvitaan uutta, nykyistä parempaa teknologiaa. Kehittämistarvetta on biomateriaalien korjuussa, materiaalin jauhamisessa ja lajittelussa sekä säätötekniikassa, jolla em. laitteita hallitaan. Perinteiset maatiloilla käytössä olevat laitteet eivät yleensä sellaisinaan sovi uudenlaisten teollisten raaka-aineiden ja tuotteiden valmistukseen.

Tutkimuksen tulokset ovat sovellettavissa helposti käytäntöön. Aiempien tietojen ja tulosten perusteella öljyvahingon torjuminen olisi edullisinta mahdollisimman varhaisessa vaiheessa. Tämä on harvoin mahdollista. Suomenlahdella lähitulevaisuudessa lisääntyvät öljynkuljetukset aiheuttavat riskin, jonka torjumiseen on varauduttava. Biomateriaaleja voidaan käyttää edullisen öljyn-torjuntajärjestelmän raaka-aineina. Tutkimuksessa käytettyjen suodatinaineiden raaka-aineita voidaan tuottaa jo nykyisin maatiloilla olevilla koneilla. Maatiloilla olevia resursseja voitaisiin käyttää tämän tutkimuksen tuloksiin perustuvan öljyntorjuntajärjestelmän kehittämiseen.

\section{Kirjallisuusluettelo}

Choi, H-M, Kwon, H-j, Moreau, J. P. 1993. Cotton Nonwovens as Oil Spill Cleanup Sorbents. Textile Research Journal. Vol. 63(4):211-218.

Groot, de, B. 1999. Alkaline Pulping of Fibre Hemp. In: Agronomical and physiological advances in hemp crops. In Advances in Hemp Research, Ed Ranalli, P. 272 p.

Gullichsen, J., Pehkonen, A., Klemetti, U. \& Pasila, A. 2000. Kuituhamppu selluloosan raakaaineena. Julkaisussa: "Pellavan monet mahdollisuudet”. Toim JÄRVENPÄÄ, M., SALO, R. Maatalouden tutkimuskeskuksen julkaisuja A 73, 88 s. Jokioinen.

Pasila, A. 1997. Dry-line -method for Flax and Hemp. NJF-Seminar 272, 22.-26.10.1997. Pärnu, Estonia.

- " - 1998. Läpivirtaussuodatin ja menetelmä läpivirtaussuodattimen valmistamiseksi. Suomalainen patentti No. 101608, 31.07.1998. Patentti- ja rekisterihallitus, Helsinki.

- " - \& Pehkonen, A. Suokannas, A. 1999. Lyhyen kuidun korjuun ja varastoinnin kehittäminen. Helsingin yliopisto, maa- ja kotitalousteknologian laitos, maatalousteknologian julkaisuja, 26 Helsinki.

- " - \& Kymäläinen, H.-R. 2000. Frost processed reed canary grass in oil spill absorption. Mol.Cryst. and Liq. Cryst. 353:1-10.

Niklas, K. J. 1992. Plant Biomechanics. 607 p. The University of Chigago Press, Chigago, USA.

Rissanen, R. \& Viljanen, M. 1998. Kasvikuitupohjaiset materiaalit lämmöneristeinä. Teknillinen korkeakoulu Talonrakennustekniikan laboratorio. Julkaisu 77. Espoo. 
SUOMEN MAATALOUSTIETEELLISEN SEURAN TIEDOTE NRO 18

VTT 1996. Tutkimusselostus öljypitoisuuden määrittämisestä kolmella suodatinaineella puhdistetusta öljyisestä vedestä. Tutkimusselostus no. KET 31/96, VTT, Espoo. 